\title{
El mural Historia de Sonora de Enrique Estrada. Un estudio formal e interpretativo a través del uso innovador de tecnológicas informáticas
}

M.H Fabián Dionisio Guerrero Saavedra

fabianpintura@hotmail.com

Dr. Leonel De Gunther Delgado

leonel.degunther@unison.mx

Universidad de Sonora

\section{Introducción}

Esta investigación se centra en el análisis y comprensión de la obra mural Historia de Sonora realizada por el artista chiapaneco Enrique Estrada en las escalinatas del Palacio de Gobierno del Estado de Sonora en los años 1982-1984 por medio de la técnica acrílico, bajo el mandato del Gobernador Samuel Ocaña García

Tras la revisión de la bibliografía se constató que son escasos los estudios que describen los métodos de trabajo de Enrique Estrada, además de la existencia de cierta inclinación por el enfoque de tipo interpretativo.

Así, el objetivo general de esta investigación consistió en analizar la dimensión formal y comprender la dimensión iconográfica del mural Historia de Sonora del artista Enrique Estrada mediante el uso de aplicaciones tecnológicas tanto de edición de gráficos como de la realidad virtual.

Finalmente, consideramos que el trabajo ofrece una perspectiva innovadora en el estudio de la plástica, ya que el empleo de tecnologías ha sido un recurso escasamente empleado con fines de análisis.

Empleo de tecnologías en el estudio de la obra artística
De acuerdo a Ruiz (2013) son muchos los investigadores que se han valido de los recursos de realidad virtual y aumentada con el objetivo de presentar información histórica o de hallazgos de patrimonios culturales.

Otros autores como Murairiu y Pretescu (1999) han implementado las tecnologías para los trabajos de estudio de conservación de murales, utilizando programas como Arcview Image Analysis software para crear mapas geográficos, así como el programa Arview 3-D Analyst, programa que permite visualizar los datos 3D para terrenos, superficies y volúmenes.

Los trabajos sobre patrimonios artísticos por medio de la realidad aumentada han ido creciendo. Entre las investigaciones se mencionan las realizadas al Museo de Bellas Artes de Rems por el equipo de investigación del Informatique et Communnications pertenecientes al Conservaitore National des Arts et Métiers de París y el proyecto por parte del Institut de Recherche en Informatique de Toulouse, las cuales han propuesto complementar la visita a un museo permitiendo superponer información virtual por medio de aplicaciones de tipo móviles que ayudan a comprender al espectador la historia no solo 
del museo, sino de la obra que se estudia, el contexto, entre otros (Ruiz, 2013)

Por otro lado, entre otros estudios que emplean tecnologías se encuentran los realizados por Ramírez (2004) el cual integra la tecnología de la realidad virtual para analizar las pinturas prehispánicas de Bonampak, proyecto que puede ser utilizado por los docentes para la explicación tanto de la arquitectura, así como del mural.

\section{Estudios sobre el mural Histo- ria de Sonora}

En el caso de Enrique Estrada, se han realizado notas digitales o ediciones impresas sobre el artista como las realizadas por Arredondo (2014), Mendiola (1 Agosto, 2010), Montiel (Septiembre 2013), Montemayor (Jueves 20 de junio de 2002), Salazar (Marzo 27, 2015 ), Sotelo (Junio 30 de 2008) Barrientos (18 Mar 2017). Específicamente del mural Historia de Sonora se han publicado algunas ediciones por autores como Tibol (1990), Moncada (1997), Romo (2014), Rodríguez (del 7 al 13 de Agosto del 2015) y nuevamente por Rodríguez (1978-1985), Luna (1998) y Lameiras (2010) en cuyas publicaciones se presenta el contexto histórico, de alegoría y significado de su obra y mural, pero sin escudriñar acerca del proceso de construcción del mural.

\section{Metodología formal- interpretativa}

Parte de la investigación nos permiten hablar de una metodología mixta, que bien podemos llamar formal-interpretativa, la primera simula, a partir de diferentes programas computacionales, mientras que, la segunda interpreta algunos aspectos simbólicos del mural.

\section{Método de simulación}

Según Anu (1997) la simulación podría definirse como lo siguiente:

En su sentido más amplio, la simulación es una herramienta para evaluar el ren- dimiento de un sistema, existente o propuesto, bajo diferentes configuraciones de interés y durante largos períodos de tiempo real, (p. 7).

De acuerdo a Jiménez (1996), la utilización de este método conlleva ocho pasos, aunque en este caso se ha modificado el método y sintetizado en 4 pasos: Análisis, Desarrollo, Implementación y Evaluación.

\section{Método iconográfico}

Para una mejor comprensión del mural se ha elaborado un análisis de tipo iconográfico. Siguiendo a Panofsky (1972) el análisis pre-iconográfico se basa en un análisis de percepción formal permitiendo reconocer la forma y el comportamiento de lo que vemos a simple vista, así como también la descripción de las imágenes y sus acciones dentro de la composición. Mientras que en el nivel iconológico se intenta conocer las tendencias esenciales de la mente humana analizando el contexto que rodea a la obra de arte.

\section{El proceso de reconstrucción del mural a través del software en 3D}

En la primera etapa de la reconstrucción virtual se utiliza el programa Adobe Photoshop con el fin de manipular y editar las fotografías.

Para realizar el modelado se utilizó 3d Max trabajando a partir de dibujos vectoriales llamados paths y su conversión en editable spline o el uso de boxes ${ }^{1}$ editadas a manera de poly ${ }^{2}$ con el fin de que este pudiera recibir algunos modificadores $^{3}$, en este caso, de tipo extrude 4 para

1 Caja primitiva creada en 3D Max

2 Poly y spline editable son objetos editables con cinco niveles de sub objetos: vértice, borde, borde, polígono y elemento. Su uso es similar al de un objeto de malla editable, con controles para manipular un objeto como una malla poligonal en varios niveles de sub objetos.

$3 \quad L o s$ modificadores de 3D Max son las herramientas esenciales que permiten cambiar la forma de los objetos.

$4 \quad$ El modificador extruir convierte una spline (forma bidimensional) en un objeto tridimensional, elevándolo en el eje Z. 
que las paredes así como la losa tuvieran un grosor. Una vez obtenido un levantamiento general del edificio, se procede a diseñar algunos elementos de ornamentación.

Sin embargo, existían dificultades técnicas al momento de realizar el mapeado: el modificador $U V W$ unwrap en $3 \mathrm{~d}$ max, por lo que se utilizó entonces el programa Blender. Finalmente una vez concluido el modelo, el proyecto es exportado en el formato $f b x^{5}$.

Una vez importado el archivo al programa de motor gráfico Unity, se procede a reinsertar los assets $^{6}$ al proyecto, como lo son edificios, objetos, pantallas, pasto, videos con el fin de darle ambientación y soporte al proyecto.

Para ir conociendo los avances del proyecto se procede a utilizar una ventana de visualización en modo de game $e^{7}$. Sin embargo, las imágenes generadas por esta cámara eran estáticas es por ello que se buscó otro tipo de opción: un controlador de personaje en primera persona ${ }^{8}$ el cual aporta varias ventajas como lo es el desplazamiento y visión de 360 grados por todo el lugar.

También fueron utilizadas técnicas de programación en C\# con el fin de generar sprites $^{9}$ de imágenes y $\operatorname{tags}^{10}$ para añadir información adicional. Para lograr que estas ventanas fueran emergentes fue necesario utilizar un componente llamado

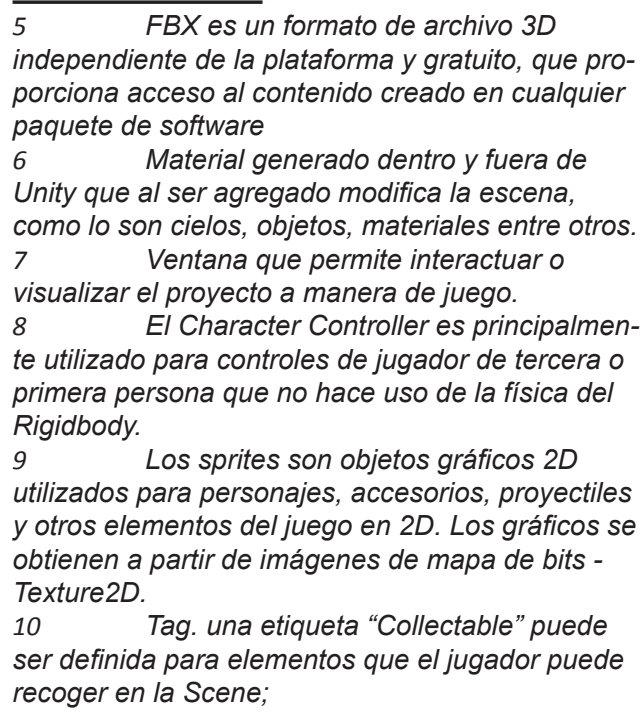

raycast ${ }^{11}$. Para lograr cambiar de la escena principal a la escena secundaria fue requerido añadir un trigger $^{12}$ a las puertas (de los edificios externos) así como un componente llamado scene switch scri$t p^{13}$.

Finalmente, cuando todo el proyecto es terminado este es exportado en extensión .exe para web.

A continuación, se describe el análisis formal a través del recorrido virtual.

\section{Análisis técnico formal}

El primer paso fue abrir el proyecto de realidad virtual para estudiar la técnica https://austenitic-shifts.000webhostapp. com/ o www.artefabianguerrero.com

Con el recorrido virtual se buscaban indicios que permitiera conocer el proceso técnico de esta obra. El espacio elegido para estudiar la técnica, el color, la textura o claroscuro se dividió en secciones relativamente amplias, pero reduciendo gradualmente hasta poder observar aquellos detalles que van desde los $5 \mathrm{~m}$ a los $10 \mathrm{cms}$.

En este caso podría decirse que la obra mural fue realizada a base de capas finísimas de pintura, en las que por medio de la superposición se logró una luminosidad, así como ciertas tonalidades y matices. Las capas fueron colocadas de forma ligera con una superposición de pintura más cubrientes y/o semi-cubrientes, dejando observar tenuemente los colores anteriormente colocados, creando un efecto poli-cromático por superposición de colores y no por mezcla de estos.

\section{Color}

Debido a que el mural virtual fue construido a partir del mapeo de fotografías con lentes panorámicos o gran angular, fue necesario insertar tags para que estas fotografías pudieran observarse acerca11 Raycast Emite un rayo, desde el punto de origen, en dirección, de longitud max Distance, contra todos los colisionadores de la escena. 12 Trigger o desencadenador consiste en un evento (una instrucción INSERT, DELETE o UPDATE emitida en una tabla asociada) y una acción (el procedimiento relacionado). 13 Scene switch script. Script para cargar escenas al Proyecto. 
mientos por medio de ventanas flotantes. La paleta utilizada en esta obra está compuesta por los colores primarios rojo, azul y amarillo y los secundarios como el naranja, verde y violeta, los colores térreos como el siena y el ocre fueron aplicados puros sobre el fondo gris y de esta manera conservan la luminosidad y la armonía.

También se obtuvieron tonos secundarios, entre ellos figuran la colocación de colores de veladura, la transposición de un tono frío sobre uno cálido, la mezcla entre colores primarios, así como la añadidura del tono negro y blanco para llevarlos a otro valor más alto o más bajo según sea la intención.

Salvo en casos excepcionales los colores como el rojo y/o el azul se aplicaron en forma saturada.

\section{Claroscuro}

Por medio del desplazamiento en el programa Unity tanto en las zonas centrales, así como en la zona norte donde se pudo advertir que la técnica utilizada por el artista para dar la ilusión de efecto volumétrico fue mediante la manipulación tonal utilizando el claroscuro, en base a un juego de sombras y luces. Por medio del recurso del claroscuro, así como el de la perspectiva Estrada pudo así generar la ilusión de dimensión y profundidad.

Analizamos dentro del software un área relativamente general, aunque representativa como la de la zona inferior derecha norte; en esta zona se pudo observar que estaba constituida de tres grises en diferentes tonalidades y así darnos una idea general del cómo estaba solucionada la totalidad de la obra, a excepción de la zona de los revolucionarios muertos en la zona norte inferior, la cual parece estar trabajada inversamente.

Existe una sección que presenta el caso de los cadáveres, situados en la sección norte inferior. La solución plástica en ellos fue invertida. Es decir, se trabajó desde un fondo oscuro modelando la luz.

\section{Texturas}

El estudio de las imágenes ampliadas en la galería virtual de la aplicación, así como aquellos videos publicados dentro de la simulación, permitió diagnosticar la presencia de texturas en diversas zonas. Mediante el recorrido virtual se observaron las texturas en distintos tipos de experimentación. A la hora de realizar la inspección del mural especialmente de algunas zonas en particular como la central, encontramos que existen áreas con algunas franjas verticales. Esto facilitó la comprensión de cómo es que el artista ha utilizado estas texturas para poder crear objetos con apariencia de materia.

De las texturas encontradas se pudo conocer que estas son únicamente visuales y fungen como una experiencia sensible, enriquecedora, pero ilusoria puesto que la textura no se encuentra realmente ahí.

Alcances y limites en el uso del software para el análisis formal del mural Todo software está diseñado para alcanzar fines específicos, en ocasiones requiere la ayuda de otros programas, además requiere de actualizaciones para corregir año tras año aquellas necesidades de diseño. A continuación se exponen las experiencias en el programa en la realización del proyecto.

\section{Ventajas}

La visualización de datos a través de las computadoras agiliza el proceso del análisis.

La interfaz de inmersión de la aplicación permite conocer el mural desde cualquier punto de exploración, sensibilizando los sentidos, caminando y observando todo en tiempo real.

Para organizar la información en la simulación 3D, se añadieron videos del mural para reforzar más el aprendizaje del usuario y darle más soporte al proyecto.

El uso de este tipo de tecnologías convierte al proyecto en un sistema lúdico e innovador en el uso de la tecnología para el estudio del mural, puesto que la información se aprende a manera de juego.

\section{Desventajas}

La realidad virtual generada en tiempo real no cumple con un papel hiperrealista, su nivel está limitado si lo comparamos 
con el videojuego.

Otro problema que cabe señalar es que no se pudo experimentar con la tecnología de Occulus Rift ya que este dispositivo externo requería ciertos requisitos ${ }^{14}$.

Análisis interpretativo del mural

Para una mejor comprensión del mural Historia de Sonora se ha elaborado un análisis de tipo iconográfico de acuerdo a la metodología propuesta por Panofsky (1972).

\section{Análisis iconológico}

En una primera etapa del método se utiliza el nivel pre-iconográfico, con el fin de describir lo que encontramos a primera vista como lo es las figuras, objetos y su relación entre estas y el escenario. A grandes rasgos, se pudiera decir que la composición del mural está dedicado a la Revolución Mexicana.

En mi opinión, el mural Historia de Sonora va más allá de lo decorativo. Esta obra no solo fue plasmada para embellecer las paredes del palacio, sino que en cierta manera esconde un trasfondo. La crítica del artista pudiera enfocarse en lo siguiente: la denuncia de que la promesa de la Revolución, bienestar y bienvivir aún no se ha cumplido. La figura de la mujer que emerge entre el caos y que ha sido interpretada como la Patria, figura en el mural de manera semi-transparente e incompleta, para dar a entender que lo que estamos contemplando es en realidad una idea que al final tiende a evaporarse como una vaga promesa.

\section{Conclusiones}

El uso de las tecnologías en el estudio del mural

El estudio de estos datos resultó ser interesante ya que al presentarse los elementos en un recorrido virtual se mejora la comprensión.

Para llevar a cabo este proyecto fue necesario utilizar el método de simulación, ya

14 NVIDIA GTX 970 / AMD R9 290 equivalente o superior compatible con HDMI 1.3.

Procesador: Intel i5 o superior. 8 GB de RAM.

$3 x$ puertos USB 3.0, además de $1 x$ puerto USB 2.0.Windows 7 SP1 de 64 bits o posterior. que este no sólo permite un análisis recursos limitados, sino que además el resultado tiene un alto impacto en el usuario final, pues permite aprender de manera visual de una manera sencilla e interactiva.

\section{El estudio técnico formal}

Con respecto a la construcción técnica en términos generales este mural fue elaborado mediante la superposición de capas de color que van de cubriente, semi-cubriente y veladuras.

Sin lugar a dudas la apreciación del color es una parte emocional de todo el proceso visual, ya que expresa aquella información visual que se ha querido transmitir fue por ello que el proyecto de realidad virtual pudo darnos idea más completa al momento de estudiar la obra.

\section{El estudio Interpretativo}

Esta simulación es de carácter lúdico debido a su tecnología inmersiva lo que permitirá un aprendizaje de gran impacto en el usuario.

\section{Perspectivas de futuro}

Los análisis por medio de programas de diseño son económicos y no invasivos comparados con los estudios de laboratorio; además que son prácticos y que pueden realizarse desde cualquier computadora y tienen la ventaja de ser lúdicos pues el usuario final aprende más sobre el tema.

Aunque el mundo creado no tiene el hiperrealismo deseado ya que es un proyecto en tiempo real, su capacidad de imitar la realidad radica en que está provoca la sensación y percepción de los elementos, es decir existen factores psicológicos implícitos como lo es la interactividad y la inmersión. 


\section{Bibliografía}

Anu, M. (1997). Introduction to modeling and simulation. In Proceeding WSC '97 Proceedings of the 29th conference on Winter simulation (7-13). Atlanta, Georgia, USA : ed. S. Andradóttir, K. J. Healy, D. H. Withers, and B. L. Nelson. Anu, M. (1997). Introduction to modeling and simulation. 7.

Arredondo, M. (2014). Enrique Estrada: García Márquez era un hombre serio. from https://www.debate.com.mx/cultura/Enrique-Estrada-Garcia-Marquez-era-un-hombre-serio-20140516-0109.html

Barrientos, A. (18 Mar 2017). Enrique Estrada: Cazando el movimiento. Recuperado http://www.vanguardia.com.mx/articulo/enrique-estrada-cazando-el-movimiento

De Luna, A. (1998). La pintura de Enrique Estrada. México DF, México: Instituto Nacional de Bellas Artes.

Lameiras, P. (2010). Enrique Estrada, Obra: 1975- 2009. (Licenciada en Historia del Arte), Centro de Cultura Casa LAMM, México.

Luna, A. (1998). La pintura de Enrique Estrada. México: Instituto Nacional de Bellas Artes.

Mateos, S., \& Gifreu, A. (2014). Reconstrucción y activación del patrimonio artístico con

tecnología audiovisual. Experiencia de Täul 1123. El profesional de la información, 23(5).

Mendiola, V. M. (1 Agosto, 2010). Tres observaciones sobre la obra de Enrique Estrada. Recuperado de

http://www.nexos.com.mx/?p=13864

Moncada, C. (1997). Sonora bronco y culto: Crónica de la cultura en Sonora de 1831 a 1997. Hermosillo, Sonora, México: Instituto Sonorense de Cultura.

Moncada, C. (2001). Dialogo con multitudes. Los murales de Sonora. Hermosillo, Sonora, México: Instituto Sonorense de Cultura.

Montemayor, C. (jueves 20 de junio de 2002). Milagro del arte que nos mira. from http://www.jornada.unam.mx/2002/06/20/19aa1cul.php?printver=1

Montiel, A. (Septiembre del 2013). Las travesías de luz. La pintura de Enrique Estrada. Casa del tiempo (71) vol. 6, época 4, 43-46.

Murariu, E. \& Petrescu F. (1999). Mural painting digital surveys. XVII CIPA Symposium: Mapping and Preservation for the New Millennium. Proceedings. Recuperado de https://www.researchgate.net/publication/261984732 Mural painting digital surveys

Panofsky, E. (1983). El significado en las artes visuales. Madrid: Alianza editorial. 
Panofsky, E. (1972). Iconografía e iconología: introducción al estudio del arte del Renacimiento (Vol. 1era edición): Westview Press.

Ramírez, B. (2004). La pintura mural prehispánica en México, Bonampak. Instituto de Investigaciones Estéticas, UNAM, ciudad de México: Departamento de Visualización y Realidad Virtual. Recuperado de

http://www.ixtli.unam.mx/node/38

Rodríguez, H. (1978-1985). La cultura en Sonora: Profesor Hernández A.

Rodríguez, H. (del 7 al 13 de Agosto del 2015). Los murales del Palacio de Gobierno de Sonora. Primera Plana.

Romo, O. (2014) from http://www.casadelasideas.com/oscar-romo/murales-encuestas-

y-esas-cosas/

Ruiz, D. (2013). La realidad aumentada y su aplicación en el patrimonio cultural. Ediciones Trea, S. L.

Salazar, J. A. (Marzo 27, 2015 ). Enrique Estrada, retratos de la historia. from http://www.statusmexico.com/w0614p/arte/enrique-estrada-retratos-de-la-historia/

Sotelo, G. (Junio 30 de 2008). Presentan en la RAC Obra Negra de Enrique Estrada. Universo. El periódico de los Universitarios. https://www.uv.mx/universo/316/arte/ arte04.htm

Storetmyr, P., \& Franz, A. (2000). Experiencies from the Use of Adobe Photoshop and DiVisual for Digital Graphic Documentantion of Mural Paintings and Exterior Stones Facades. Report Raphael I Nidaros Cathedral Restoration 98/034198 Project 69.

Tibol, R. (1990). Los murales del Palacio de Gobierno Sonora Mágica 89, 10.

\section{Anexos}

Proyecto WebGI hospedado en la siguiente dirección https://austenitic-shifts.000webhostapp.com/ o www.artefabianguerrero.com Instrucciones para la navegación en modo web: Utilización de teclas ASDWX. (W) adelante, (S) atrás, (A) izquierda, (D) derecha. Tecla shift para correr hacia adelante manteniendo aplastada tecla (W) y tecla tabuladora para brincar. Para el cambio de escena a escena, atravesar las puertas. 